\title{
APROPRIAÇÕES DA IMIGRAÇÃO E DO TRABALHO RURAL NO POEMA MARTIM CERERÊ E NA REVISTA S.PAULO
}

\author{
APPROPRIATIONS OF IMMIGRATION AND RURAL WORK IN THE \\ POEMA MARTIM CERERÊ AND IN THE MAGAZINE S.PAULO
}

\author{
George Leonardo Seabra Coelho (UFT) ${ }^{1}$
}

RESUMO: Nesse artigo, discutiremos como Cassiano Ricardo apropriou-se do passado histórico paulista, mais especificamente do processo de imigração e da produção agrícola para compor seu poema Martim Cererê (1927), assim como para elaborar as reportagens da revista S.Paulo (1936). Ao traçar esse caminho, defenderemos a necessidade de dar atenção à relação entre o autor e sua obra a partir das concepções de Roger Chartier (2002). Consideramos que a interação entre autor, obra e os diversos campos expõe a complexidade da análise literária na abordagem histórica. Nesse sentido, este trabalho é pautado pela perspectiva histórica do texto e na complexidade da obra, onde compreenderemos as formas como a imigração e o trabalho rural foram apropriados no texto literário e publicitário.

PALAVRAS-CHAVE: literatura; história; representação

ABSTRACT: In this article, we will discuss how Cassiano Ricardo appropriated São Paulo's historical past, more specifically the immigration process and agricultural production to compose his poem Martim Cererê (1927), as well as, to write the reports of the magazine S.Paulo (1936) . In tracing this path, we will defend the need to pay attention to the relationship between the author and his work based on the concepts of Roger Chartier (2002). We consider that the interaction between author, work and the different fields exposes the complexity of literary analysis in the historical approach. In this sense, this work is guided by the historical approach of the text and the complexity of the work, where we will understand the ways in which immigration and rural work were appropriated in the literary and advertising text.

KEYWORDS: literature; history; representation

\footnotetext{
* Esse artigo é parte da Tese de Doutorado intitulada "O bandeirante que caminha no tempo: apropriações do poema 'Martim Cererê' e o pensamento político de Cassiano Ricardo". Essa tese foi orientada pela Prof. ${ }^{a}$ Fabiana de Souza Fredrigo e defendida no Programa de Pósgraduação em História da Universidade Federal de Goiás em 2015.

${ }^{1}$ É Pós-Doutor em História pela UNIRIO, e Professor Adjunto do curso de Licenciatura em História e do Programa de Pós-Graduação em História das Populações Amazônicas da Universidade Federal do Tocantins-Porto Nacional.
} 
Introdução

No campo dos estudos dedicados à ocupação econômica das terras paulistas, nos deparamos com três grandes eixos interpretativos, vejamos: as pesquisas destinadas à expansão das fronteiras cafeeira no século XIX e início do século XX (DEFFONTAINES, 1936; MILLIET, 1939; MONBEIG, 1945; CAMARGO, 1952; PRADO JR., 1969); os estudos que discutem a decadência do trabalho escravo, a inserção de imigrantes e o impacto do trabalho livre na produção agrícola (LAMOUNIER, 1988; EISENBERG, 1989; MARTINS, 1990; KOWARIC, 1994; MOURA, 1998; MESSIAS, 2003); e, por fim, as análises que debatem os impactos econômicos da construção de ferrovias no estado paulista (COSTA, 1976; CECHIN, 1978; MELLO, 1982; SILVA, 1986; EVANGELISTA, 1987; CANO, 1990).

A partir desses três eixos analíticos - a expansão da fronteira agrícola, a inserção do trabalhador imigrante e a construção de ferrovias - esses pensadores pretendiam compreender o rápido e crescente processo de ocupação econômica das terras paulistas. Outro aspecto desses estudos, parte do pressuposto de que a ocupação das terras paulistas estaria voltada para a ampliação da economia mercantil, onde a passagem da produção canavieira para a cafeeira representou uma espécie de dinamismo, o qual deu origem ao processo de industrialização e ao crescimento da estrutura produtiva de São Paulo. Com o intuito de ampliar esse entendimento, os estudos dedicados ao papel das pequenas e médias lavouras vêm se firmando como quarto eixo. Esses estudos não negam o papel central das grandes propriedades rurais, mas ressaltam que as pequenas e médias lavouras também foram importantes nas dinâmicas econômicas paulistas (OLIVEIRA, 1997; TOSI, 1998; CHABARIBERY, 1999).

Frente a essa breve exposição referente aos vieses analíticos referentes ao desenvolvimento econômico paulista, nosso intuito nesse artigo é tratar a apropriação dessas dinâmicas econômicas na literatura modernista, mais especificamente no poema Martim Cererê (1927) de Cassiano Ricardo. Para 
tanto, veremos como esse literato paulista lançou mão de elementos históricos referentes à imigração e o trabalho na composição de seu poema e, consecutivamente, na elaboração da publicidade da revista S.Paulo (1936). Examinaremos, ao longo desse estudo, os modos como esse intelectual paulista se apropriou do imigrante e do trabalhador rural para poetizar e propagandear o desenvolvimento econômico do estado de São Paulo.

Neste artigo, entendemos que o "consumo cultural" de um texto é tomado como produção de representações que não são idênticas às que o produtor ou o autor investiram na obra. Para entender essa ideia, Roger Chartier (1990) propõe a noção de "outra produção". Conforme tal princípio, o historiador francês construiu as bases para a noção de apropriação, a qual será útil para compreendermos os usos do passado histórico nos textos poéticos e publicitários. Seguindo essa perspectiva, concordamos com Chartier (2002) ao afirmar que a significação dos textos depende das capacidades, dos códigos e das convenções de leitura das diferentes comunidades e distintos públicos, assim como das "variações entre a significação, a interpretação e as apropriações plurais que sempre inventam, deslocam, subvertem" os significados (CHARTIER, 2002: 259).

Tendo em vista os comentários sobre o conceito de apropriação de Roger Chartier (2002) é que entenderemos como Cassiano Ricardo apropriouse do passado histórico paulista. De forma mais clara, veremos como o poeta incorporou o processo de imigração e do trabalhador rural na escrita do poema Martim Cererê (1927) e na composição das reportagens da revista S.Paulo (1936). Como dito no início desse estudo, quatro grandes eixos historiográficos buscaram dimensionar o desenvolvimento econômico paulista: a expansão das fronteiras agrícola; a inserção do imigrante na produção rural; a construção da malha ferroviária; e, por fim, a dinâmica da pequena propriedade rural. Ao longo desse artigo, veremos como o poema Martim Cererê (1927) de Cassiano Ricardo já havia desenvolvido esses temas na década de 1920.

Segundo Antônio Celso Ferreira (2009: 61), em razão da sua "riqueza de significados para o entendimento do universo cultural”, os textos literários 
podem ser vistos como materiais propícios a múltiplas leituras. Para esse autor, o tratamento da fonte literária na pesquisa histórica, especificamente da obra poética, demanda um esforço adicional. Compartilhando dessa posição, elaboramos procedimentos para estabelecer o diálogo entre os textos e o mundo circundante. Para tanto, propomos o diálogo entre a leitura do poema Martim Cererê (1927) e sua apropriação na revista S.Paulo (1936). Essa proposta demonstrará que a escrita do poema interagiu com várias outras dimensões culturais, uma vez que partimos da noção "de circularidade cultural, ou seja, de que há um intenso intercâmbio de ideias, imagens e formas de expressões" (FERREIRA, 2009: 82).

Para apresentar ao leitor os resultados de nosso estudo, dividimos esse artigo em três partes. Na primeira seção, intitulada "O poema Martim Cererê: o papel do imigrante na formação social brasileira", contextualizamos o poema Martim Cererê no campo literário brasileiro e suas peculiaridades. Também ressaltamos a importância dos debates referentes a composição racial do brasileiro no início do século XX. Por último, apontamos como os imigrantes foram apropriados na narrativa do poema em tela. Esse percurso foi importante para demonstrar como Cassiano Ricardo apropriou-se do imigrante para representar a composição social brasileira. Na segunda seção, intitulada "O mundo rural ricardiano: o trabalhador rural e a marcha da soldadesca verde", demonstramos como o poeta se apropriou do mundo rural como etapa da formação da nacionalidade, a qual se daria pelo avanço da lavoura cafeeira rumo ao interior do território. Essa narrativa foi fortemente marcada pelo poder econômico da lavoura de café, de modo que o trabalhador rural, particularmente o imigrante foi o grande responsável pelo sucesso da economia cafeeira. $\mathrm{Na}$ terceira seção, intitulada "Reescrita do poema M.C. na revista S.Paulo: o trabalhador imigrante e a produção cafeeira", apresentamos como foi organizada a revista S.Paulo (1936), seu corpo editorial e sua finalidade. Na sequência trabalhamos com a reescrita do poema neste suporte publicitário, onde analisamos as reportagens e o uso das imagens e fotomontagens como linguagem para a comunicação entre o autor e o leitor. Esse recurso foi 
fundamental para compreender como ocorreu a apropriação do poema pelo mensário, em especial como a figura do imigrante e do trabalhador rural surgiu como personagem que representaria o sucesso da produção cafeeira paulista.

Ao traçar esse caminho, perceberemos a necessidade de dar atenção à relação entre o autor e sua obra. Relação essa que pode ampliar os elos entre o campo literário, o campo publicitário e o campo social brasileiro. Nesse sentido, a interação entre autor, obra e os diversos campos expõe a complexidade da apropriação da literatura na abordagem histórica, da mesma maneira que propicia dar a atenção necessária à constituição da própria fonte. Este trabalho foi pautado em dois pressupostos - o exame histórico do texto e a complexidade da obra -, os quais deram suporte para compreendermos as formas como a imigração e o trabalhador rural foram apropriados nesses textos. Com base nessa problemática, convidamos o leitor a nos acompanhar na leitura do poema Martim Cererê (1927) e da revista S.Paulo (1936).

O poema Martim Cererê: o papel do imigrante na formação social brasileira

Estudos direcionados à literatura brasileira do primeiro quartel do século XX concebem que, após as atitudes demolidoras propostas pela Semana de Arte Moderna de 1922, surgiram - no final da década de 1920 e início da década de 1930 - produções literárias mais sedimentadas. Nesses anos, vieram a público três obras fundamentais da literatura modernista: Martim Cererê $\hat{~}^{2}$ (1927), de Cassiano Ricardo; Macunaíma (1928), de Mário de Andrade; e Cobra Norato (1931), de Raul Bopp. Ao lançar mão do poema M.C. (1927) como fonte para o estudo histórico, torna-se necessário apresentar algumas especificidades.

Uma primeira singularidade está no fato de ter sido publicada - nove anos após seu lançamento - a sexta edição, fato raro no mercado literário, especialmente em se tratando de um poema. Como contraponto desse "sucesso" editorial, somente em 1937 as segundas edições de Macunaíma e Cobra Norato

\footnotetext{
${ }^{2}$ Doravante $M . C$.
} 
seriam publicadas ${ }^{3}$. Outra faceta do poema M.C. está no fato de o poeta ter feito, a cada edição, alterações profundas em seu texto ${ }^{4}$. Antes de darmos continuidade a este estudo, é importante lembrar um último dado quanto ao M.C. Essa obra não é um livro de poemas, e sim um poema único formado por materiais díspares, que pretendeu abranger o país inteiro por meio da narrativa mítica da origem da nação (MARTINS, 1973).

Ao apreciar a escrita particular do poema M.C., trabalhamos com a hipótese de que, acima de seu valor para a história da literatura brasileira ou para o estudo da obra em si - como expressão do espírito artístico individual -, essa obra enseja ao historiador o status de um importante registro sobre a apropriação do processo histórico da imigração e do trabalho rural em uma obra de ficção. Para ampliarmos o conhecimento histórico sobre as relações entre literatura e história no seio do campo de atuação de Cassiano Ricardo, delimitamos nosso estudo na comparação entre as seis primeiras edições 1927, 1928, 1929, 1932, 1934, 1936 - do referido poema.

A narrativa do poema M.C. é dividida em seis partes. Na primeira seção, encontramos a descrição da terra em eterna desordem, do mundo selvagem, da fauna, da flora e dos indígenas. Na segunda parte, o branco é inserido na narrativa. Essa inserção pretende deixar explícito que o Brasil necessitaria do branco colonizador para se civilizar. Assim como consagrou poemas sobre o indígena e o branco, Cassiano Ricardo também poetiza a "terceira raça": o negro. Após o encontro harmônico da tríade racial, na quarta seção surgem os "gigantes de botas" - os bandeirantes - que conquistaram o território. Para resolver o problema da mestiçagem na formação racial do brasileiro, Cassiano

\footnotetext{
${ }^{3}$ É importante levantarmos outras variáveis comparativas entre o M.C. e essas duas obras para vermos alguns indícios do "sucesso" editorial do poema de Cassiano Ricardo. As seis edições do M.C. somam mais de cinco mil exemplares, contra pouco mais de dois mil de Macunaíma e Cobra Norato juntos. Além da quantidade de exemplares, apenas a segunda edição do romance de Mário de Andrade foi publicada por uma editora de sucesso, enquanto o M.C. teve três edições publicadas pela Editora Hélios e uma pela Livraria José Olympio Editora.

${ }^{4}$ Poderíamos, à primeira vista, supô-las decorrentes das revisões comuns à publicação de novas edições. Contudo, nas revisões ao longo das edições Cassiano Ricardo alterou não somente o número de poemas, mas também a escrita. Assim, vemos que na edição de 1927 eram 57 poemas em 167 páginas; na de 1928, 42 poemas em 127 páginas; na de 1929, 47 poemas em 126 páginas; na de 1932, 51 poemas em 139 páginas; na de 1934, 55 poemas em 180 páginas; e na edição de 1936, 60 poemas em 227 páginas.
} 
Ricardo insere o imigrante europeu na quinta parte do M.C. Além de poetizar a origem étnica, o nascimento dos "gigantes de botas", a chegada do imigrante e a personalidade do trabalhador rural, a última parte do poema canta o espaço urbano moderno. Com esse desfecho, o poeta estabelece os laços entre o passado e o presente. Observemos, de agora em diante, as formas como o imigrante e o trabalhador rural foram apropriados pelo poeta para representar o dinamismo da economia paulista.

Para idealizar a composição racial brasileira, Cassiano Ricardo inseriu o indígena, o branco e o negro como as primeiras raças que deram origem à nacionalidade. Para resolver o problema da mestiçagem na sociedade brasileira, o poeta inseriu o imigrante na narrativa. Segundo Marly Silva da Motta (1992), o Centenário da Independência foi um marco no processo de constituição da identidade racial da nação, tanto por demarcar os traços de semelhança, quanto por demarcar as diferenças com o europeu. A autora concebe que nas comemorações, a questão racial emergiu como um tema caro para a construção de uma sociedade moderna, a qual dependia da (re)construção da nação. Com o intuito de tentar resolver os dilemas quanto a intepretação sobre a nacionalidade partindo da questão racial, o Instituto Histórico e Geográfico Brasileiro (IHGB) cumpriu um importante papel nestes anos.

No que se refere a esse debate no interior do Instituto, Noé Freire Sandes (2011) considera que o IHGB buscou organizar e dar sentido a marcha dos acontecimentos históricos com base no estudo das três raças. De acordo com o autor, o IHGB aprofundou o estudo da atuação dos portugueses no período colonial, principalmente a dos administradores coloniais e no período da emancipação. Em relação aos indígenas, abre-se uma polêmica com os indigenistas do século XIX acerca da sua identificação como portadores da identidade nacional; o Instituto defendia a ideia de que "o indígena deveria ser tomado como objeto de pesquisa histórica e etnográfica", mas mesmo assim, "atestando a superioridade da raça branca" (SANDES, 2011: 96). Quanto aos negros, apenas lamentavam-se "os males oriundos da escravidão, delineando, sob o signo da ausência, a participação do negro em nossa história" (SANDES, 
2011: 96). Sendo assim, prevaleceu a reflexão sobre o papel da miscigenação derivada da imigração europeia e as teses do branqueamento racial.

No intuito de interpretar o processo imigratório do final do século XIX e início do século XX, Helaine Nolasco Queiroz (2010) pondera que os escritores modernistas, ao construírem suas narrativas identitárias, também absorveram a problemática da imigração europeia em suas produções. Em alguns textos "Verdeamarelos",, por exemplo, o fenômeno da imigração europeia ganhou destaque em virtude de São Paulo ter recebido um número maior de imigrantes. Acreditava-se que a imigração intensificaria o problema da formação nacional, visto que ela podia desestabilizar a incipiente nacionalidade. Por outro lado, Cassino Ricardo, Plínio Salgado e Menotti del Picchia - a tríade do Modernismo "Verdeamarelo" - procuram resolver o dilema afirmando que a massa imigratória deveria ser assimilada, transformando-se em novo tipo étnico.

O pressuposto da assimilação dos estrangeiros europeus ao caldeamento racial brasileiro pode ser claramente percebido na leitura do poema M.C. Logo na epígrafe do livro encontramos essa problemática. Escrita por Plínio Salgado, a epígrafe anuncia:

Se ele foi o curumi das tabas, o moleque da senzala, deve ser também o italianinho das nossas fazendas de café e o escoteiro das nossas escolas. É a criança travessa. E, como criança, é a própria imagem da Pátria (SALGADO, 1927b: 1).

Dessa epígrafe retiramos uma questão fundamental; as "fazendas de café" finalizam a continuidade histórica iniciada com o encontro racial. Essa construção pode ser tida como uma tendência regionalista do poema e expressão do habitus dos escritores paulistas da década de 1920. Para os limites

\footnotetext{
5 O ponto alto, em termos de sistematização dos pressupostos do "Verdeamarelismo", foi a coletânea $O$ Curupira e o Carão (1927a), editada pela Hélios. Essa coletânea, publicada há menos de quatro meses do M.C., reuniu artigos - escritos entre 1922 e 1927 - de Cassiano Ricardo, Menotti del Picchia e Plínio Salgado. Annateresa Fabris (1994: 238) defende que na luta entre o Curupira e o Carão, divulgada nesta coletânea, inaugurou a luta do presente contra o passado, mas o espírito estético do presente no qual o grupo verde-amarelo se inspirava não era o "extremismo" de Mário de Andrade nem da "estética importação" de Oswald de Andrade.
} 
deste trabalho, lançamos mão da noção de habitus de Pierre Bourdieu (2008). Para o sociólogo francês, o investigador deve estar atento à estrutura do espaço social no qual os discursos são produzidos e à estrutura da constituição do campo. Segundo o autor, a noção se habitus é importante para lembrar que os agentes têm uma história individual e coletiva e, por isso, estão imersos em um sistema aberto às disposições oferecidas pelas experiências. Assim, o funcionamento de um habitus não depende apenas da natureza do lugar em que ele age, pois se o campo é outro, o mesmo habitus produz efeitos diferentes (BOURDIEU, 2012). Nesse sentido, as classificações e as estratégias coletivas, assim como as reivindicações regionalistas propostas por Cassiano Ricardo, são táticas pelas quais o poeta se apropriou dos bens simbólicos produzidos em diversos campos a serviço do ideário do grupo "Verdeamarelo".

No que concerne a análise da epígrafe, o que chama a atenção não é o regionalismo explícito pela produção cafeeira e, sim, o implícito. Se a colonização brasileira foi feita por portugueses, por que trazer o "italianinho" como elemento racial? Essa problemática nos leva a propor outras três questões. Seria por que a imigração italiana e a produção do café ocorreram com maior força em São Paulo e, por isso, afirmariam o distanciamento com a colonização do Nordeste? Ou ainda: seria para lançar as bases de uma visão do passado que justificaria a particularidade paulista frente ao todo nacional? Seria, também, uma forma de o poeta assimilar as leituras referentes ao papel negativo do português durante a colonização? Defendemos que ambas as proposições se completam em uma trama que associa a valorização de símbolos regionais paulistas como plataforma de idealização da nação para o futuro: produção cafeeira e imigração europeia.

Após o encontro racial entre o indígena, o branco e o negro, Cassiano Ricardo insere o imigrante como "quarta raça" na narrativa do M.C. O poeta anuncia "o prenúncio da Terra nova" que irá "acolher os foragidos de outras Pátrias" (RICARDO, 1927b: 55). No poema, "Tende toda esperança. Vos que entrais!", o poeta descreve a chegada dos imigrantes que "desceram na manhã dos navios [...] trazendo velhos dias de realeza" (RICARDO, 1927b: 13). Ao 
apropriar-se dos imigrantes europeus para temperar o caldeamento racial do brasileiro, o poeta elenca o Porto de Santos como a porta por onde todos os destinos "vêm procurar um só destino" (RICARDO, 1927b: 138). Os imigrantes europeus, segundo o plano poético de Cassiano Ricardo, trouxeram suas "esperanças misturadas com lembranças" e "braços para a lavoura" (RICARDO, 1927b: 14). E, assim, os imigrantes formaram um "exército colorido" que conquistou o sertão com suas "enxadas a brilhar ao sol" (RICARDO, 1927b: 131). Segundo o poeta, é por esse caminho que as "quatro raças/que depois de todos os ódios/e de todas as lutas humanas/irão fundir-se pelo amor numa só raça [...] buscando o mistério da raça futura" (RICARDO, 1927b: 160).

Através destas linhas extraídas do M.C. percebemos que é pelo trabalho e pelo amor entre as raças que se formará a "raça futura". Com essa afirmativa, vemos que a concepção racial oriunda dos debates de seu tempo está presente no texto poético; contudo, Cassiano Ricardo insere, no poema, preocupações quanto à imigração não apenas relacionada ao branqueamento da nação, mas quanto ao processo de formação da "raça futura". É importante deixar claro que esse olhar referente a origem e a formação racial do povo brasileiro não foi uma inovação específica do poema de Cassiano Ricardo, pois o debate em torno da formação étnica já era presente na literatura desde a Geração de 1870. Segundo Mônica Pimenta Velloso (2010), muitos escritores do início do século XX assimilaram o caráter mestiço da cultura, no entanto, em muitas delas predominava a visão pessimista da nacionalidade. A grande maioria dos literatos liam a brasilidade através da cartilha do darwinismo social, distinguindo superiores e inferiores em função das etnias, de modo que a teoria do branqueamento racial era predominante ${ }^{6}$.

\footnotetext{
${ }^{6}$ Lilia Schwarcz (1993) salienta que as teorias raciais europeias receberam uma entusiasmada acolhida no Brasil, mas essa receptividade não significou que tenham permanecido tais quais eram abordadas no continente europeu. A autora acentua que nessa negociação, os intelectuais brasileiros - Belisário Penna, Nina Rodrigues e Arthur Neiva - atualizaram o que combinava e descartaram o que era problemático para a construção de um argumento racial coerente com a sociedade brasileira (SCHWARCZ, 1993). Para a autora, essas ideias foram produzidas em diferentes estabelecimentos de ensino e pesquisa, incluindo: Museus Etnográficos Brasileiros, Institutos Históricos e Geográficos, Faculdades de Direito e Faculdades de Medicina.
} 
Aos poucos, nos contos, na poesia e nas danças, o povo brasileiro começava a ser identificado na figura do indígena, do africano e do europeu, ou seja, do mestiço. A partir da década de 1920, com o enfraquecimento dos pressupostos deterministas raciais, as controvérsias sobre os efeitos da mestiçagem fora reelaborada pelos intelectuais brasileiros, em especial, pelos escritores verde-amarelos. No manifesto "Verdeamarelo" de 1929, assinado por Plínio Salgado, Menotti del Picchia, Cassiano Ricardo, Alfredo Ellis e Candido Motta Filho, somos capazes ver mais de perto a concepção racial desses escritores. Segundo o manifesto, a "Nação é uma resultante de agentes históricos. O índio, o negro, o espadachim, o jesuíta, o tropeiro, o poeta, o fazendeiro, o político, o holandês, o português [...] o francês" (O ACTUAL..., 1929: 4). Para esses escritores, o Brasil é "um país de migração e continuaremos a ser refúgio da humanidade por motivos geográficos e econômicos” (O ACTUAL..., 1929: 4). Segundo Cassiano Ricardo em seu M.C., o Brasil é o único país, onde "o drama" vai "cessar a dispersão de todas as raças para a elaboração do homem-síntese” (RICARDO, 1927a: 69).

É possível perceber a valorização da mestiçagem na narrativa do poema M.C. e do referido Manifesto. Essa valorização se justifica pelo fato de que Cassiano Ricardo e outros verde-amarelos se inspiram nas teorias do mexicano José Vasconcelos. Segundo Regina Aída Crespo (2003), na década de 1920, ocorreu a aproximação entre Brasil e México a partir do envio da Missão Mexicana às comemorações do I Centenário da Independência, chefiada por José Vasconcelos, Ministro da Educação Pública daquele país. De acordo com a autora, a viagem de Vasconcelos ao Brasil inaugurou uma etapa de contatos entre alguns intelectuais brasileiros e mexicanos, que se prolongou até a década seguinte. No livro A raça cósmica (1926), a autora reconhece que Vasconcelos desenvolveu uma imagem idílica do Brasil, afirmando que as paisagens eram perfeitas, não existia miséria, as pessoas eram amáveis e o governo era composto de homens cultos. Durante a estadia no Brasil, a autora revela que Vasconcelos cativou as elites intelectuais brasileiras, ocupando as primeiras 
páginas dos jornais mais importantes da capital do país com seus discursos integracionistas e ibero-americanistas.

Regina Aída Crespo (2003) nos lembra que José Vasconcelos elegeu a América como a terra mais adequada à abertura para novas culturas; já, para Cassiano Ricardo e outros "Verdeamarelos", o Brasil seria o lugar ideal. Para justificar a afirmação de que no Brasil se encontrará a "raça futura", esses escritores deixavam claro que se apoiam na "opinião bem fundamentada do sociólogo mexicano Vasconcelos" (O ACTUAL..., 1929: 4). No manifesto "Verdeamarelo", esses escritores defendiam que do Brasil sairia "a "quinta raça $^{7}$ a 'raça cósmica', que realizar[ia] a concórdia universal, porque [,essa nova raça era] filha das dores e das esperanças de toda a humanidade" (O ACTUAL..., 1929: 4). Ao inserir a tese da miscigenação vasconsceliana como atributo dos povos da América, os escritores brasileiros buscavam uma forma de encaixar o Brasil no conjunto das nações latino-americanas. Ao agirem desta forma, esse grupo de escritores reunidos em torno do "Verdeamarelismo" especialmente Cassiano Ricardo - almejou realizar esse encaixe, pois se autodenominavam modernos, sendo assim, pretendiam colocar em ação suas práticas discursivas ao defenderem uma arte com função social e política.

Como visto, encontramos no poema M.C. e no manifesto "Verdeamarelos" a equivalência temática entre as teses defendidas por Cassiano Ricardo e o campo intelectual latino-americano. Nesse sentido, fica claro o intercâmbio de Cassiano Ricardo não só com a matriz historiográfica do IHGB, com as propostas regionalistas, nacionalistas e temáticas do Modernismo brasileiro, mas com o campo intelectual latino-americano. Concebemos que esse "consumo cultural" orientou a interpretação racial representada no poema de Cassiano Ricardo, a qual defendia que a miscigenação racial promovida pela imigração europeia seria a maior contribuição do Brasil para a humanidade. De acordo com o próprio poeta em

\footnotetext{
${ }^{7}$ No argumento da "quinta raça" de José Vasconcelos, Luciana Melo (2013) percebe o pragmatismo voltado para a valorização do mestiço. Essa proposta se choca frontalmente com as teorias vigentes no período, pois o escritor mexicano "se posiciona contra as argumentações tecidas pelo spencerismo, que moldava as presunções raciais da época não só contra raças de cor, mas também contra os povos mestiços" (MELO, 2013: 63).
} 
artigo publicado na coletânea $O$ Curupira e o Carão (1927a), o "brasileiro tem um destino formidável a cumprir", ou seja, a "elaboração do homem-síntese" (RICARDO, 1927a: 66).

Retornando o tema da imigração e seu papel para a formação da "raça futura" no poema M.C., vemos que o processo imigratório está espalhado por toda a narrativa; tal inserção não sofre alterações nas seis versões analisadas do M.C. Reconhecemos que a grande inovação do poeta com a inserção do imigrante na constituição do brasileiro é a definição das origens raciais brasileiras opostas ao Peri, ao Jeca e à tríplice formação étnica. De acordo com Mário da Silva Brito (1971), Peri era o protótipo da literatura indianista, negada integralmente pelos "Verdeamarelos", pois era posta como falsa. Já o Jeca Tatu representava o brasileiro incapaz e fatalista, paralisado ante a paisagem e a vida; e, por isso, também foi negado. Outra recusa "Verdeamarela" referia-se aos três grupos étnicos (indígena, branco e negro), pois se prendia ao Parnasianismo de Olavo Bilac. Em substituição a essas três acepções vistas como negativas pelos "Verdeamarelos", Cassiano Ricardo defendia a inserção da imigração como mais um elemento racial importante para a formação da cultura brasileira.

Um dos caminhos para construir a ponte interpretativa sobre o papel do imigrante na formação do brasileiro seria o cosmopolitismo paulista. Na concepção de Cassiano Ricardo, a cidade paulista proporciona que cem raças se debatam no seu xadrez etnológico. Essa construção também encontrava seus argumentos no cosmopolitismo paulista defendido por Menotti del Picchia, um dos principais parceiros de escrita de Cassiano Ricardo. Segundo Mário da Silva Brito (1971), Menotti del Picchia defendia que em virtude das levas imigratórias que chegaram a São Paulo, elas modificaram visceralmente a ambiência étnica do povo brasileiro. De acordo com o autor, Menotti del Picchia proclamou o novo tipo de homem resultante da mistura dos sangues, pois a raça brasileira não estava plenamente formada. Essa nova raça se formaria somente através da mistura que se vem processando e na qual entraram todas as universais virtudes positivas dos imigrantes. Menotti del Picchia entendia que a força étnica do 
português, do silvícola e do negro fora vencida pelos imigrantes; em outras palavras, o cosmopolitismo paulista havia levado esses escritores a descrerem da trindade racial.

Essa interpretação marcou profundamente a apropriação da imigração no M.C., de forma que o imigrante se integrou ao poema como colaborador dessa nova nação; pelo amor e pelo trabalho. $\mathrm{O}$ imigrante viera para contribuir com o trabalho nas lavouras de café e, depois, na cidade industrial. Implicitamente, o imigrante veio para contribuir com a formação da família, pois na fase rural da narrativa, a musa de desejo do eu poético sempre é uma mulher de origem europeia: russa, húngara, francesa ou italiana. Independente da questão da mão de obra e do amor, o imigrante foi apropriado simbolicamente para contribuir com a formação da "raça cósmica" idealizada por José Vascancelos e apropriada pelos escritores "Verdeamarelos", em particular, por Cassiano Ricardo.

O mundo rural ricardiano: o trabalhador rural e a marcha da soldadesca verde

Além de poetizar a participação do imigrante na formação social do brasileiro, o poema também abarca o trabalhador rural como personagem que compõe a formação da nacionalidade. De acordo com o poeta, com o fim do "tropel de gigantes", as Bandeiras se transfiguraram no avanço da lavoura de café rumo ao interior do território. Passada a poetização das aventuras dos bandeirantes que demarcaram o "retrato verde físico da nação" (RICARDO, 1927b: 55), o eu poético narra a próxima fase histórica do Brasil, a qual está fortemente marcado pela lavoura e as plantações de café.

A parte que canta à produção cafeeira na versão de $1928^{8}$ é apresentada com uma ilustração. Nela, vemos o ambiente rural, as casas e os cafezais disciplinadamente alinhados avançando sobre a serra. Do mesmo modo que a conquista do território foi realizada pelos "gigantes de botas", a produção

\footnotetext{
${ }^{8}$ Em 1928, chega oficialmente ao público a primeira edição de $M$. C. com ilustrações assinadas por Di Cavalcanti.
} 
cafeeira seria a reencenação do "espírito bandeirante". A referida ilustração reproduz muitos enunciados do poema: a plantação, a serra e as casas simples. A imagem que ilustra o poema potencializa imageticamente o discurso poético, uma vez que insere elementos textuais como, por exemplo, as casas, os cafezais e os morros.

Figura 1 - Ilustração da quinta seção M. C. (1928).

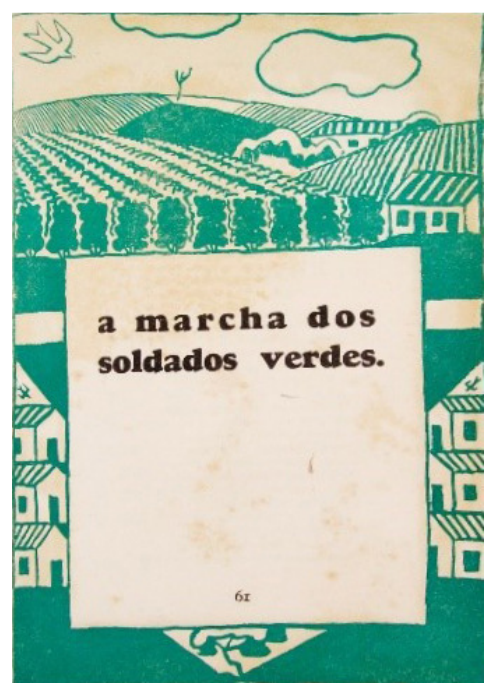

Fonte - Martim Cererê (1928)

Para representar o mundo rural, Cassiano Ricardo poetiza o ambiente visual da fazenda - os monjolos, as casas, a queimada, os animais soltos no quintal -, as festas populares e os imigrantes. Todos esses recursos contribuem para delinear a "marcha dos soldados verdes" e apresentar ao leitor os cafezais e o trabalhador rural imigrante como participantes da marcha que ocuparia o território. Desse momento em diante, Cassiano Ricardo anuncia que:

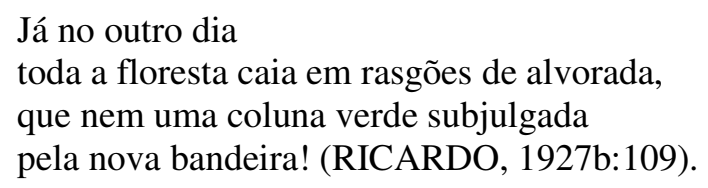

Apesar da arrancada, o "sertão continuava a dizer" que, aqui, "ninguém entra, quem manda sou eu!" (RICARDO, 1927b: 111). Até que um dia tudo emudeceu, pois, "o país claro que saiu de dentro do sertão" marchou de novo e estava "á espera apenas/de um grito anunciador, de uma voz que o 
convid[asse]" (RICARDO, 1927b: 111). Na versão de 1928 do M.C., o poeta insere um poema que anuncia que essa voz chegou para levar:

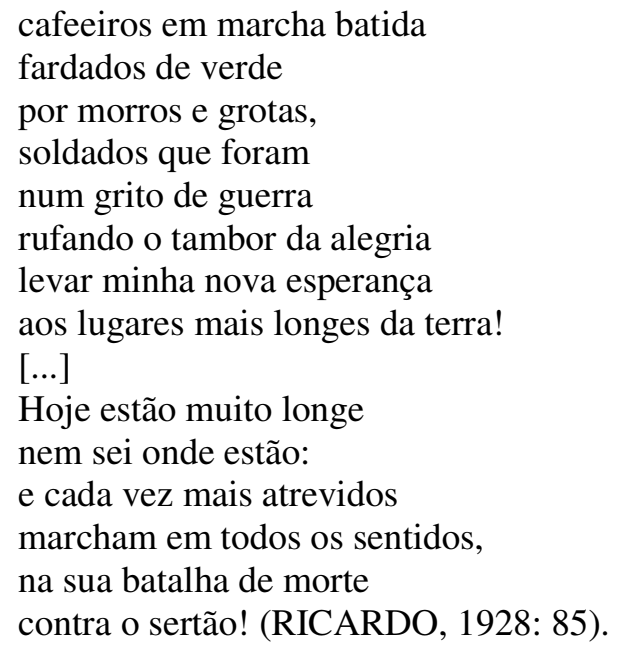

O poeta constrói uma representação militarizada dos "cafezais em marcha" (RICARDO, 1927b: 129), de modo que:

O cafezal é a soldadesca verde que salta morros na distância iluminada um-dois, um-dois, de batalhão em batalhão, na sua arremetida acelerada contra o sertão (RICARDO, 1927b: 130).

No poema M.C., a "sensação desconhecida" (RICARDO, 1927b: 84), "esse desejo, esse destino de caminhar" (RICARDO, 1927b: 85) que espera "um grito anunciador" (RICARDO, 1927b: 111) impulsiona a retomada do que ficou no passado. Essa retomada de uma sensação esquecida revive sob o comando dessa soldadesca verde, pois:

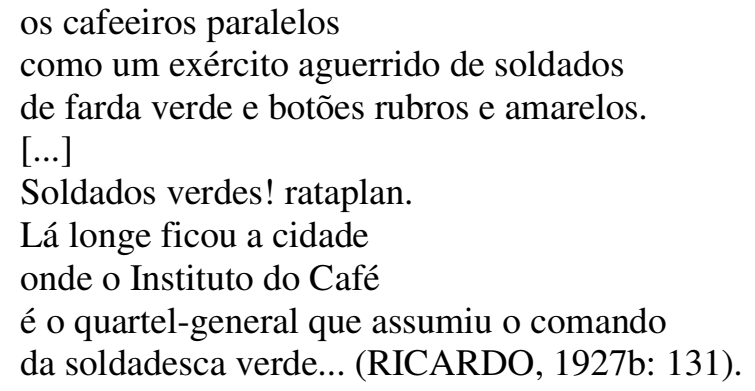

No poema "Moça tomando café" inserido na versão de M.C. de 1936, o eu poético idealiza uma cena num "salão de Paris", onde a "linda moça, de olhar gris, toma café", embora ela não saiba: 
que há um mar azul, antes da sua xícara de café

[...]

E que antes do navio longo há uma terra do sul;

e antes da terra um porto, em contínuo vaivém,

com guindastes roncando na boca do trem

$[\ldots]$

E antes do porto há um trem madrugador

Sobe-desce da serra a gritar, sem parar

[...]

E antes da serra está o relógio da estação...

$[\ldots]$

E antes dessa estação se estende o cafezal.

E antes do cafezal está o homem

$[\ldots]$

O homem sujo de terra (RICARDO, 1936: 203).

Não esqueçamos que o texto "Moça tomando café" foi inserido somente na versão de 1936 do M.C., de forma que o trabalhador rural passa a ser inserido na narrativa como um fator primordial para a produção. Ao longo das versões do poema, Cassiano Ricardo realça a valorização dos trabalhadores rurais, especificamente do imigrante, pois lembra que antes do "cafezal está o homem" que "derrubou sozinho a floresta brutal” (RICARDO, 1936: 203).

A imagem do camponês quieto, triste e calado foi redefinida no poema ao longo das reescritas. A partir das edições trintistas, o poeta redefine o costume do sertanejo de ficar "quieto e imóvel". No M.C., o eu poético relata: você o "está vendo assim, meio triste, mas é ele quem pega a viola e quem canta mais bonito que um pássaro" (RICARDO, 1936: 147); você o está vendo "manso e calmo, porque esta é sua hora de descanso" depois que derrubou "o mato a golpes de machado" (RICARDO, 1936: 147); e você que o está vendo "calado.../e é melhor não mexer com ele, é melhor mesmo/deixá-lo assim [...] sossegado" (RICARDO, 1936: 148). Sobre o trabalhador rural, o eu poético exalta: "é ele quem monta o picaço a galope/e some na poeira da estrada a hora certa/de trabalhar, quando a manhã o convida/a tomar parte no espetáculo da vida" (RICARDO, 1936: 147). Esse trabalhador rural é o "herói obscuro" que acorda na "manhã branca do futuro" e chega com o "povaréu madrugador" para as "horas rudes de trabalho" (RICARDO, 1936:160). 
Nas duas primeiras versões do poema M.C., a apropriação do trabalhador rural era superficial, já que o homem do campo era basicamente apropriado para cantar os amores vividos. Por outro lado, da edição de 1929 em diante, o poeta reintroduz o homem do campo com mais uma distinção: o trabalho. Em outras palavras; nas duas primeiras edições (1927 e 1928), o homem do campo somente era inserido no texto para rememorar as paixões, da versão de 1929 em diante, o trabalhador rural começa a ser inserido como aquele que produz, uma vez que ele passa a ser associado ao imigrante.

No que se refere a poetização dos cafezais, o poeta canta a sensação de conquista da terra sentida através da "soldadesca verde/que salta morros na distância/iluminada/um dois, um dois de batalhão/em batalhão" na "bárbara arremetida para o oeste" (RICARDO, 1927b: 129-130). Os "cafeeiros paralelos" representados na figura 1 são associados a "um exército aguerrido de soldados" (RICARDO, 1927b: 131). Esses novos desbravadores repetem a aventura dos "gigantes de botas", mas, ao contrário daqueles, não estão isolados; eles têm os "fios telegráficos" que contam "com voz de gente/a cotação da bolsa/a hora oficial/o preço do café” (RICARDO, 1927b: 134). Essa marcha "inaugura uma nova estrada" e seus postes levam os "fios telegráficos sobre os ombros" (RICARDO, 1927b: 131). Para o poeta, a "civilização tomou de assalto o caminho da onça" (RICARDO, 1927b: 131), e o espaço primitivo cedeu lugar para a lavoura ligada por fios telegráficos. Essa tensão entre o mundo primitivo e o mundo moderno é amenizada quando a civilização encobre o "mistério selvagem" com a "fumaça de um trem" (RICARDO, 1927b: 130). Esse mundo rural preenchido pela modernização é representado pelos "exércitos verdes" que trabalham para que as máquinas de "dentes de aço" (RICARDO, 1927b: 136) transformem a natureza primitiva.

$\mathrm{O}$ poeta insere em seu poema as transformações impulsionadas pelo início da industrialização que, por sua vez, segundo a concepção de Cassiano Ricardo fora promovida pela produção cafeeira tocada pelo braço imigrante. Após o ambiente selvagem ser conquistado pela civilização, o eu poético pergunta: "E depois? Os bois puxando de dois em dois [...] e depois? Os fordes 
escandalosos a encher com o barulho dos séculos o silêncio" da "terra cabocla" (RICARDO, 1927b: 136). E mesmo com o preenchimento do espaço selvagem pela "soldadesca verde", ainda é possível sentir a "sensação desconhecida" de caminhar, pois o "espírito bandeirante" renova-se na produção cafeeira.

Essas representações consolidam o elo entre o primitivo e o moderno iniciado com o encontro racial ocorrido no descobrimento. Ambos os extremos - primitivo e moderno - permanecem interligados por uma continuidade do "espírito bandeirante" que se transfere do mundo mítico para o mundo rural e, consecutivamente, espera a chegada do mundo moderno. Na seção reservada à "soldadesca verde", o poeta constrói sua narrativa através do desprezo da história enquanto processo, o que Mircea Eliade (1993) chama de "mecanismo da construção de arquétipo" por meio da repetição. O poeta, em diferentes temporalidades históricas, consegue imitar as ações míticas do herói. Nesta imitação das ações heroicas, Cassiano Ricardo procura abordar esse modelo arquetípico com a maior fidelidade possível ao longo da narrativa.

No que se refere à definição da noção de representação, Roger Chartier (2002) afirma que se deve dar atenção às condições de produção, às diferentes relações entre a obra e seu criador, entre a obra e sua época e entre as diferentes obras da mesma época. Tal proposta parte do "consumo" cultural como "outra produção", que é um espaço aberto às literaturas múltiplas. A partir da noção de “outra produção", o historiador francês constrói as bases para a noção de apropriação como compreensão dos usos e das interpretações dos textos. De acordo com esse ponto de vista, a significação dos textos depende das capacidades, dos códigos e das convenções de leitura das diferenças comunidades e diferentes públicos. A partir dessa exposição, notamos que as noções de representação, práticas e apropriações propostas por Roger Chartier (2010) nos auxiliam no entendimento da representação do mundo rural encontrada no poema M.C. Por esse motivo, as representações, as práticas discursivas e as apropriações simbólicas realizadas pelo poeta garantiriam que o imigrante fosse incluído no processo histórico de formação nacional. Sendo assim, o poeta se apropriou de uma representação específica sobre o imigrante 
para construir uma versão mítico-poética da história nacional, em especial, do processo de expansão das fronteiras territoriais brasileiras.

Ao reencenar a marcha rumo ao sertão, Cassiano Ricardo mitifica os lavradores imigrantes como aqueles que irão retomar a aventura bandeirante, não mais na conquista do território, mas na ocupação econômica do espaço primitivo. Essa nova marcha predestinada promovida pelos lavradores imigrantes civilizaria a terra e reviveria o "espírito bandeirante"; sendo assim, encontramos novamente a supressão do "tempo profano" e o retorno ao "tempo mítico" na construção dos arquétipos. As plantas humanizadas na figura do lavrador imigrante através da prosopopeia revivem a marcha dos "gigantes de botas" e, com essa metáfora, a "soldadesca verde" que invadiu o "sertão bruto" perdeu a qualidade de etapa histórica do desenvolvimento econômico paulista, para se tornar a marcha que caminha através do eterno presente.

Mesmo com o espaço rural sendo preenchido pela modernidade dos "fordes escandalosos" e pela a modernização do espaço rural, as simbologias relacionadas à tradição agrária ainda são bastante representativas no poema em tela. Nas versões do M.C. de 1932, 1934 e 1936, Cassiano Ricardo incorporou as lembranças de infância e dos amores vividos no ambiente rural, entrelaçando-as à vida moderna. Esse recurso, segundo Luiza Franco de Moreira (2001), buscou contrastar a memória da criança e a memória do adulto para amenizar o confronto entre a infância rural e a maturidade urbana. Dessa forma, afirmamos que o poeta criou o contraponto entre os opostos: presentepassado e cidade-campo.

Reescrita do poema M.C. na revista S.Paulo: o trabalhador imigrante e a produção cafeeira

A revista S.Paulo circulou em 1936 sob a direção de Cassiano Ricardo, Menotti del Picchia e Levém Vanpre. Também compunha o corpo editorial Theodor Preising e Benedito Junqueira Duarte como fotógrafos, e contava com a colaboração de Lívio Abramo como responsável pela produção gráfica. A revista também contava com textos em inglês traduzidos por J. T. W. Sadler, 
tendo como redatores Osmar Pimentel e Francisco de Castro Neves. O mensário foi impresso pela Grafficars, gráfica de Romiti e Lanzara, sendo mensal até o oitavo número, passando a ser bimestral nos dois últimos.

Esse mensário tinha uma função bem definida: divulgar o governo de Armando de Salles. A leitura dessa revista é de suma importância para percebermos como ocorreu a interação entre várias formas de textualidade - $\mathrm{o}$ poema, o discurso publicitário e as imagens - e as interações entre o campo artístico e o campo político, uma vez que a estrutura das notícias se apropriou da narrativa do poema M.C. Veremos, de agora em diante, as formas como o corpo editorial da revista S.Paulo apropriou-se do M.C. e deslocou os enunciados poemáticos para o texto publicitário. Consideramos que nesse novo suporte, a imagem unida ao poema, fatalmente, lhe daria novo sentido e cativaria um novo público.

Essa forma de relação autor-obra-público não é uma novidade promovida por Cassiano, mas uma expressão das mudanças na comunicação de massa do século $X X$. $O$ século $X X$ se conforma como a era da reprodutibilidade, como bem lembra Walter Benjamin (1955). Nele, ocorre uma mudança não apenas tecnológica, mas uma mudança na forma de perceber e expressar o mundo. Segundo o autor, a obra de arte sempre foi reprodutível, mas a reprodução técnica da obra de arte foi algo novo. Para o autor, no início do século $\mathrm{XX}$, a reprodução atingiu um nível tal que conquistou o seu próprio lugar entre os procedimentos artísticos e publicitários. Com base nessas associações estabelecidas pelo autor, podemos analisar as maneiras como o corpo editorial da revista S.Paulo arquitetou os vínculos entre o trabalhador imigrante e a riqueza da produção cafeeira.

Segundo os redatores do mensário, o café é a bebida "das multidões" e "degustado pelos povos de todas as raças" (A MAIOR..., 1936: 6). No texto poético e publicitário, uma das faculdades da produção cafeeira é a perspectiva da fusão racial realizada pelo trabalho. Na reportagem "Imigração estrangeira", o corpo editorial defende que o estado de São Paulo é a "região do mundo que oferece maiores possibilidades ao imigrante de profissão agrícola" 
(IMIGRAÇÃO..., 1936: 13). De acordo com os redatores, essa atração para o trabalhador estrangeira se dá por alguns motivos: fertilidade da terra, boas condições meteorológicas, estradas de ferro e de rodagem para escoamento da produção, apoio técnico para a produção, salários compensadores e o baixo preço das terras. Na reportagem "Braços para a lavoura", o mensário transcreve o pronunciamento do governador de São Paulo Armando de Salles, onde o chefe do executivo estadual enaltece o avanço da produção do café paulista. Segundo o governador, o crescimento da produção cafeeira fez com que o governo reestabelecesse "as correntes imigratórias subsidiadas, reatando uma velha tradição" de São Paulo (BRAÇOS..., 1936: 14).

As notícias sobre o reatamento das correntes imigratórias impulsionadas pela produção agrícola paulista, também são acompanhadas por uma série de imagens, as quais potencializam a informação para o público. Em uma dessas imagens, vemos claramente a representação da chegada do "exército de imigrantes" para trabalhar na lavoura:

Figura 2 - Chegada dos imigrantes

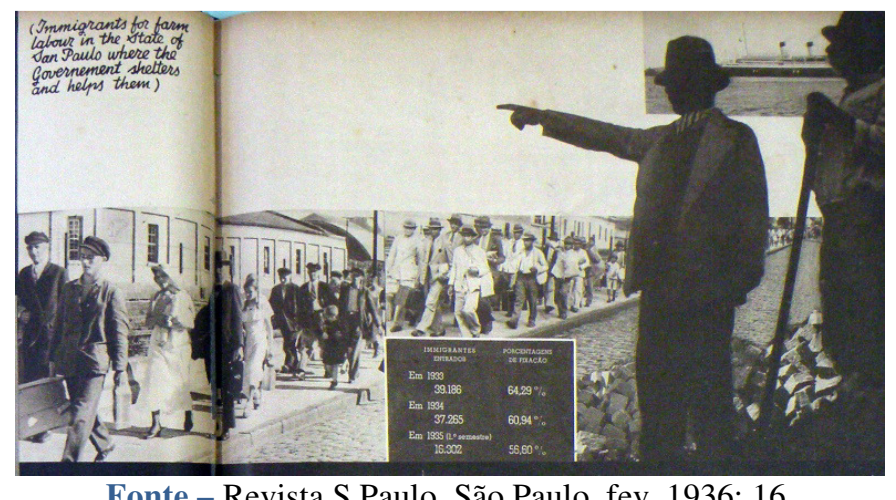

Essa imagem ilustra uma reportagem em página dupla, intitulada "Imigração estrangeira", cujos gráficos e tabelas comparam o número de imigrantes que chegaram à São Paulo entre 1933 e 1935. Na composição desta imagem, foi utilizado o recurso da fotomontagem formada a partir da união de quatro fotografias: a de um navio, na parte superior esquerda, que destaca a chegada dos imigrantes; outras duas imagens unidas que representam o 
desembarque; e outra destaca um homem coordenando a chegada do "exército de imigrantes". Trata-se do recurso que Annateresa Fabris (2003) aponta como caráter político da fotomontagem e sua forma de expressão. Em outras palavras, para que o significado político pretendido chegasse ao público, as fotomontagens mesclavam, em uma mesma composição, o caráter ficcional e os efeitos realistas, os quais tinham como função conferir credibilidade à mensagem (FABRIS, 2003). Segundo a autora, o caráter político desse recurso provoca um poder de persuasão que a fotografia por si só era incapaz de alcançar. Desta forma, a relação que se assume com a fotografia é a de uma arte que expressa a verdade (não várias verdades, mas uma), uma vez que ela concretiza as transformações, tornando-as reais para os leitores (FABRIS, 2003).

Na revista S.Paulo, é patente o processo ideológico de construção da notícia e a associação da imagem a um texto, tendo como objetivo reforçar a informação configurada a partir da montagem fotográfica. Conforme mostra a figura 2, as quatro fotografias unidas pela fotomontagem dão a impressão de que o fato está realmente ocorrendo, ao mesmo tempo em que unem diversas realidades poetizadas no M.C. No que concerne às ações do governo de Armando de Salles para impulsionar a economia rural, o discurso publicitário divulgado pela revista S.Paulo apropria-se de enunciados encontrados no texto poético: o café é o que civiliza, desbrava e une todas as raças pelo trabalho. Todos esses enunciados econômicos são postos como intrínsecos ao "espírito bandeirante", o qual impulsionaria o projeto econômico paulista. Nesse sentido, o papel dos imigrantes já poetizados no M.C. são apropriados e transportados para o texto publicitário para divulgar as ações do governo de Armando de Salles, assim como, para justificar a prosperidade econômica de São Paulo.

Tanto no poema "Moça tomando café" - transcrito na reportagem da revista S.Paulo - inserido na versão de 1936 do M.C., quando no mensário, a economia cafeeira é descrita desde o trabalho do agricultor nos cafezais, a seleção das sementes, o transporte até o consumo. Todas essas etapas podem ser apreciadas nessa fotomontagem reproduzida pela revista S.Paulo: 
Figura 3 - Plantio, colheita, exportação e o consumo do café

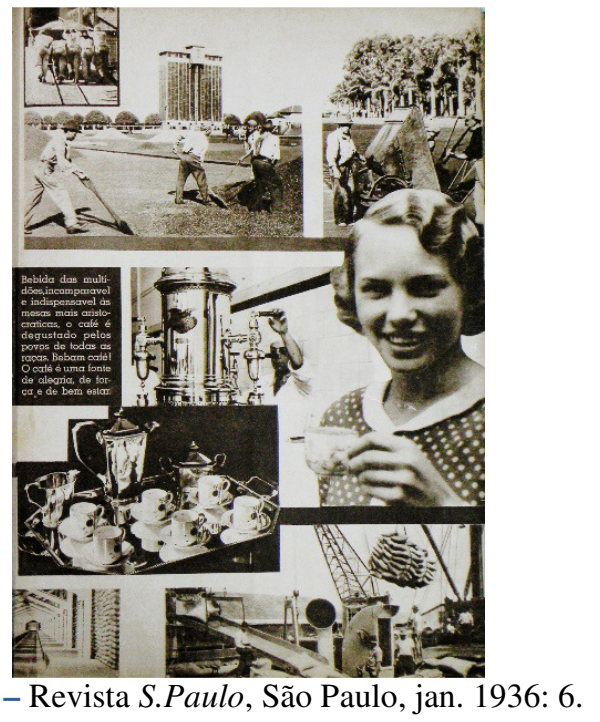

Trazendo a temática da produção cafeeira e da imigração para o texto publicitário, os redatores defendem que nessa atividade encontram-se "criaturas oriundas de todos os quadrantes do universo" (EDITORIAL, 1936: 1); por essa razão, o Brasil havia oferecido "ao mundo o primeiro exemplo da completa fusão étnica, criando o novo tipo humano, liberto dos preconceitos de cor, credo e de origem" (EDITORIAL, 1936: 1). Reproduzindo o discurso poético na revista, os redatores afirmam que no solo brasileiro se formaria a "raça cósmica" a partir da união entre o indígena, o branco, o negro e o imigrante. As ideias de que na América se formaria outra raça através da miscigenação, exerceu forte influência na escrita do M.C. e continuou exercendo na composição desse mensário dirigido por Cassiano Ricardo.

Em diversas reportagens, a produção cafeeira foi denominada como "exército verde", no qual todos os lavradores estavam "irmanados no trabalho nobre e fecundo" (BRAÇOS..., 1936: 14). Em outra reportagem, os redatores parabenizavam os "cuidados que os lavradores paulistas dispensam" a sua produção, quer "na colheita, quer na secagem, quer na exportação" (BRAÇOS..., 1936: 12). Essas reportagens foram ilustradas com imagens do trabalhador manuseando o café, notemos: 
Imagem 4 - Agricultor secando o café

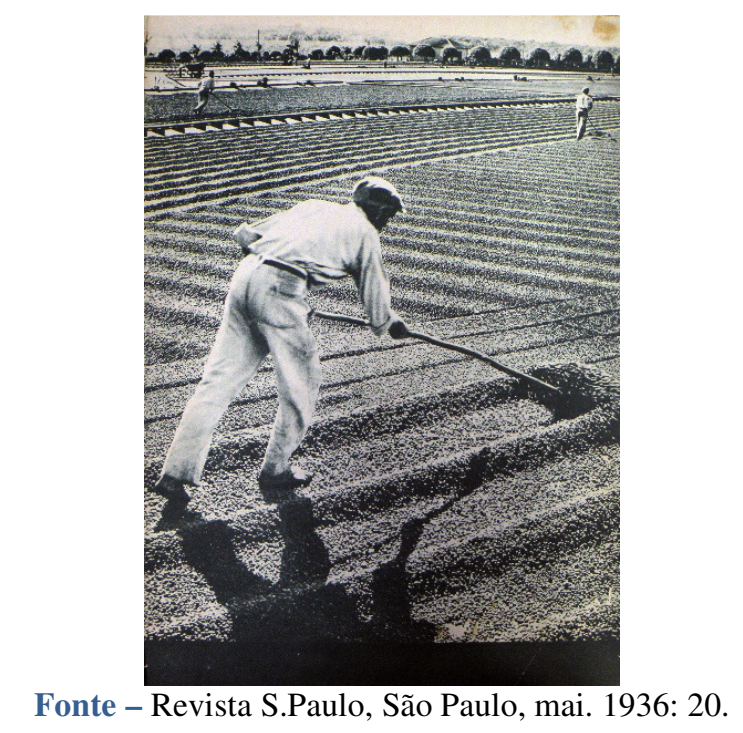

Figura 5 - Agricultor peneirando o café

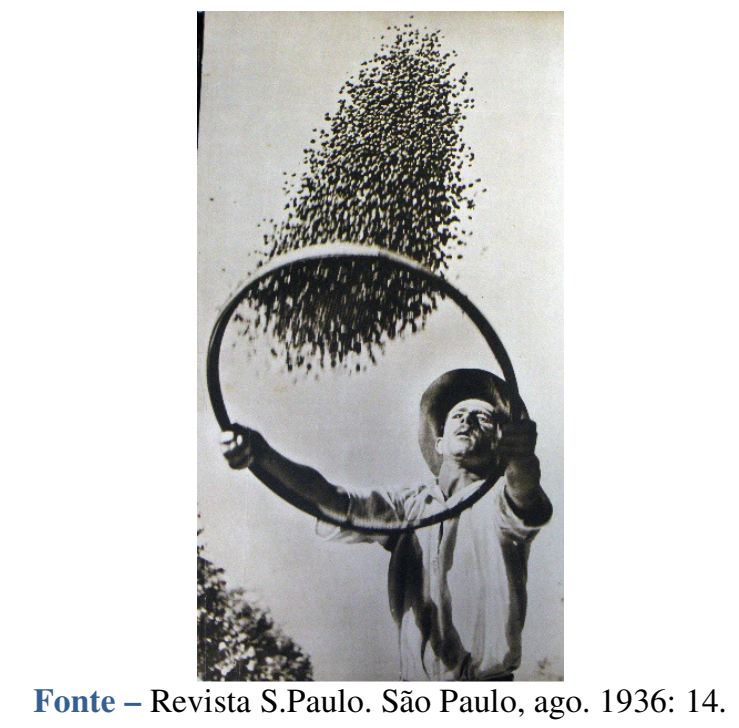

No que se refere a assistência técnica na produção do café, a reportagem "Cafés finos" sugeriu uma espécie de "oração religiosa" que o produtor deveria repetir:

Cafeicultores do Brasil! Cuidai de colher em boas condições; vigiai com o máximo cuidado os trabalhos no terreiro ou nos secadores; atentai em que a máquina esteja bem regulada, para que os trabalhe sem prejudicar o produto; expurgai as 
impurezas o máximo possível. Assim vosso trabalho será recompensado (CAFÉ..., 1936: 19).

De acordo com as reportagens, o avanço da lavoura que "desbrava, civiliza e fecunda o sertão" manifestava "o critério de disciplina e organização que caracteriza São Paulo" (EDITORIAL, 1936: 1). No intuito de qualificar o processo de constituição da economia nacional, os redatores afirmavam que "o café que civilizou o país [...] fixou suas populações rurais, fez surgir as cidades [...] Suas possibilidades [...] atraíram o braço forasteiro, concorrendo para adensar a variegada massa demográfica da nação" (EDITORIAL, 1936: 1). De acordo com os redatores, a "derrubada do sertão bruto" para a "investida geométrica dos cafezais" e o "arremesso dos andaimes para a construção da nossa metrópole" refletiam o "conflito humano com a natureza", ou seja, a civilização urbana foi mais um "extraordinário milagre dos nossos cafezais" (EDITORIAL, 1936: 1).

$\mathrm{Na}$ capa do número 2 da revista S.Paulo, uma fotomontagem apresentava o trabalhador rural como constituinte do elo entre o espaço rural e o espaço urbano, vejamos:

Figura 6 - $\mathrm{O}$ trabalhador rural como elo entre o campo e a cidade

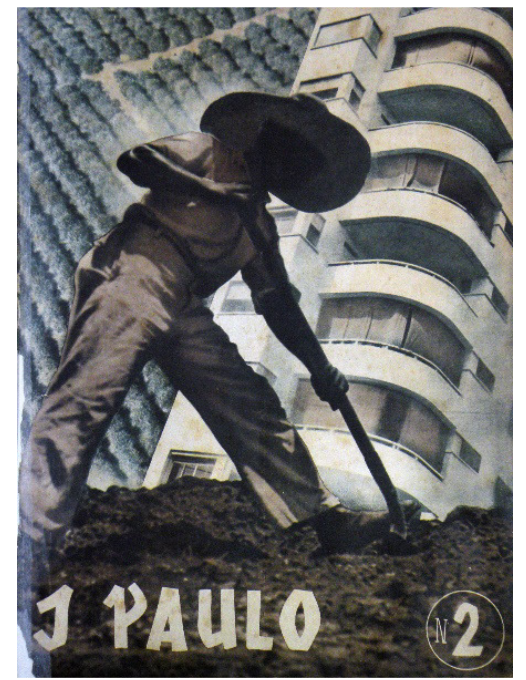

Fonte - Revista S.Paulo, São Paulo, fev. 1936. 
Nesta imagem, vemos, de um lado, uma plantação de café (o meio rural) - com as plantas bem alinhadas, representando disciplina e riqueza - e, do outro, um arranha-céu, representando o meio urbano com o que há de mais moderno em arquitetura; em meio a esses dois espaços, o trabalhador rural com sua enxada. Esta e outras imagens inseridas no mensário comunicavam eficazmente a apropriação dos enunciados encontrados no poema M.C. para potencializar as intenções publicitárias da revista. Analisando a mesma imagem, Maria Cláudia Reis Silva (2014) admite que essa fotomontagem foi outro exemplo de um tipo de recurso que apareciam nas ilustrações da revista: o contra-plongé. Segundo a autora, essa técnica foi utilizada para aumentar e conscientemente engrandecer o objeto principal de uma cena, fotografando o elemento principal de baixo para cima e, dessa forma, enobrecer - no caso dessa imagem - a riqueza advinda do café.

Por meio da relação entre o poema, o texto publicitário e a imagem intercambiadas na revista S.Paulo, os redatores transportavam os enunciados poéticos do M.C. para esse suporte. Através da reescrita do M.C. em outro suporte potencializado com as fotomontagens, o poema de Cassiano Ricardo conheceu novas montagens, ampliando a percepção dos símbolos que ele buscava exprimir, sobretudo as representações do imigrante e do trabalhador rural. Através da apropriação do M.C. pelos redatores da revista S.Paulo, vemos a tentativa de divulgação do poema para um público heterogêneo. Por essa razão, concordamos com Maria Cláudia Reis Silva (2014) ao afirmar que o discurso visual desse mensário fazia com que a sua publicação em grande formato $(30 \mathrm{cmx} 40 \mathrm{~cm})$ fosse acessível a todos: letrados, analfabetos e estrangeiros.

\section{Considerações finais}

Como dito no início desse estudo, quatro grandes eixos interpretativos dimensionavam o desenvolvimento econômico paulista: à expansão da fronteira agrícola paulista; a inserção do imigrante no trabalho agrícola; a construção da 
malha ferroviária; e, por fim, a dinâmica da pequena propriedade rural. Ao longo desse artigo, vemos como o poema M.C. de Cassiano Ricardo já havia abordado esses temas em sua obra literária na década de 1920. A expansão da fronteira agrícola foi poetizada na figura dos cafezais que avançavam pelo território e reeditavam a expansão do território promovida pelos bandeirantes durante o ciclo do ouro no século XVIII. Cassiano Ricardo também se apropriou da malha ferroviária em seu poema ao idealizar que a economia cafeeira asseguraria o desenvolvimento econômico do estado paulista e, com ele, a industrialização. E, finalmente, a pequena propriedade foi inserida em sua obra para representar o empreendedorismo do imigrante, um mundo rural idílico e o papel desempenhado pelo trabalhador rural para a economia agrícola de São Paulo.

No poema, a inserção do imigrante completaria o caldo racial da formação do brasileiro, onde a inspiração em José Vasconcelos daria origem a ideia de formação de uma raça futura no Brasil, ou seja, a criação do "homem síntese". Em Cassiano Ricardo, o suporto "homem síntese" foi vinculado à modernidade trazida pelo café. Essa construção simbólica buscava superar definitivamente as concepções atrasadas apoiadas no determinismo da raça de fins do século XIX. No que diz respeito ao "consumo cultural" das teses vasconcelianas no poema M.C., defendemos que ela viabilizou uma resposta ao problema posto à sociedade brasileira da época. Tal problema havia sido apresentado já no final do século XIX e início do século XX, o qual girava em torno da identidade nacional. Tais posições tomavam a pureza da raça como essência do sucesso ou não da Nação, no que a intelectualidade buscou uma explicação e, consequentemente, uma saída para o atraso que permeava essa sociedade mestiça e herdeira do colonialismo. Sendo assim, o "consumo cultural" das ideias vasconcelianas - em especial a tese da "raça cósmica" - por Cassiano Ricardo abriu caminho para resolver as questões identitárias e raciais nacionais, de modo que o imigrante seria um ingrediente fundamental para o caldeamento racial que formaria o brasileiro. 
Como foi possível notar, também, na revista S.Paulo, os redatores, na tentativa de divulgar as ações da administração de Armando de Salles, buscaram uma estética moderna para apresentar suas notícias aos leitores. Esse recuso foi fundamental para concretizar a apropriação do poema M.C. pelo mensário, em especial a figura do imigrante e do trabalhador rural. A leitura do poema e da revista foi de suma importância para percebermos como ocorreu a interação entre várias formas de textualidade - o poema, o discurso publicitário e as imagens - e as interações entre o campo artístico e o campo político, o qual buscou dar sentido através da apropriação da imigração e do trabalhador rural.

Seguindo as sugestões de Roger Chartier (1990), entendemos que o "consumo cultural" das ideias defendidas pelo IHGB, por José Vasconcelos e pelo conjunto de escritores "Verdeamarelos" foram tomadas como "outra produção" que não eram idênticas às de seus produtores. Tal prisma se alinha à afirmação que as obras produzidas em uma ordem específica escapam dos autores e ganham existência ao serem investidas pelas significações que os diferentes públicos lhes atribuem, ou seja, "os usos e apropriações impostas pelas formas de 'representação' do texto" (CHARTIER, 2002: 259). Com essa afirmação, entendemos que a "outra produção" empreendida por Cassiano Ricardo, a qual se dá através da apropriação do poema M.C. na revista S.Paulo. Desse modo, o imigrante se tornou - no campo simbólico - o elemento racial necessário para compor o tipo racial brasileiro, isto é, o "homem síntese".

\section{Referências}

A MAIOR INDÚSTRIA AGRÍCOLA DO MUNDO. Revista S.Paulo, São Paulo, jan. 1936, p. 6.

BENJAMIN, Walter. A obra de arte na era da sua reprodutibilidade técnica. Disponível em: <http://ideafixa.com/wpcontent/uploads/2008/10/texto_wbenjamim_a_arte_na_era_da_reprodutibilidad e_tecnica.pdf> Acesso em: 26/04/2020

BOURDIEU, Pierre. A Economia as Trocas Linguísticas: O que Falar Quer Dizer. $2^{\text {a }}$ Ed. - São Paulo: Editora da Universidade de São Paulo, 2008. 189 p.

BOURDIEU, Pierre. O sociólogo e o historiador. Trad. Guilherme João de Freitas Teixeira. Belo Horizonte-MG: Autêntica Editora, 2012. 134 p. 
BRAÇOS PARA A LAVOURA. Revista S.Paulo, São Paulo, ago. 1936, p. 1214.

BRITO, Mário da Silva. Duas faces de Cassiano Ricardo. In: BRAYNER, Sônia. Cassiano Ricardo. Rio de Janeiro: Civilização Brasileira; Brasília: Instituto Nacional do Livro, 1979. p. 151-161.

CAFÉS FINOS. Revista S.Paulo, São Paulo, mai. 1936, p. 19.

CAMARGO, José Francisco de. Crescimento da população no estado de São Paulo e seus aspectos econômicos (Vol. 1). São Paulo: Universidade de São Paulo, 1952.

CANO, Wilson. Raízes da Concentração Industrial em São Paulo. São Paulo: Hucitec, 1990.

CECHIN, Jose. A construção e operação das ferrovias no Brasil do século XIX. 1978. 124 f. Dissertação (mestrado) - Universidade Estadual de Campinas, Instituto de Filosofia e Ciências Humanas, Campinas, SP. 1978.

CHABARIBERY, Denyse. Inovação e desigualdade no desenvolvimento da agricultura paulista. 1999. 205f. Tese (doutorado) - Universidade Estadual de Campinas, Instituto de Economia, Campinas, SP, 1999.

CHARTIER, Roger. História cultural: entre práticas e representações. Rio de Janeiro: Difel-Bertrand, 1990. 239 p.

CHARTIER, Roger. À Beira da Falésia. A História entre Certezas e Inquietudes. Trad. Patrícia Chittoni Ramos. Porto Alegre: Ed. Universidade/UFRGS, 2002.

CHARTIER, Roger. A história ou a leitura do tempo. Trad. de Cristina Antunes. - $2^{\mathrm{a} e d .}-$ Belo Horizonte: Autêntica Editora, 2010.

COSTA, Wilma Peres. Ferrovias e trabalho assalariado em São Paulo. 1976. 170 f. Dissertação (mestrado) - Universidade Estadual de Campinas, Instituto de Filosofia e Ciências Humanas, Campinas, SP. 1976.

CRESPO, Regina. Cultura e política: José Vasconcelos e Alfonso Reyes no Brasil (1922-1938). Revista Brasileira de História. São Paulo, v. 23, n 45, 2003, p. 187-208

EDITORIAL. Revista S.Paulo, São Paulo, fev. 1936, p. 1.

EISENBERG, Peter. Homens esquecidos. Escravos e trabalhadores livres no Brasil, séculos XVIII e XIX. Campinas: Unicamp, 1989. 
ELIADE, Mircea. Mito do eterno retorno. Trad. José A. Ceschin. São Paulo: Mercuryo, 1992.

EVANGELISTA, José Geraldo. Lorena no século XIX. São Paulo: Governo do Estado, 1987.

FABRIS, Annateresa. Modernidade e modernismo no Brasil. Campinas, SP: Mercado de Letras, 1994.

FABRIS, Annateresa. A fotomontagem como função política. Disponível em: $<$ http://www.scielo.br/scielo.php?pid=S0101-

90742003000100002\&script=sci_arttext> Acesso em: 08/04/2020

FERREIRA, Antônio Celso. Fonte fecunda. In: PINSKY, Carla Bassanezi \& LUCA, Tania Regina de. (orgs.) O Historiador e suas Fontes. São Paulo: Contexto, 2009. p. 61-91

IMIGRAÇÃO ESTRANGEIRA. Revista S.Paulo, São Paulo, fev. 1936, p. 13.

KOWARIC, Lúcio. Trabalho e Vadiagem. A Origem do Trabalho Livre no Brasil. São Paulo: Paz e Terra. 1994.

LAMOUNIER, Maria Lúcia. Da escravidão ao trabalho livre. A lei de locação de serviços de 1879. Campinas: Papirus, 1988.

MARTINS, José de Souza. O Cativeiro da Terra. HUCITEC: São Paulo, 1990.

MARTINS, Wilson. O modernismo. $4^{\text {a }}$ Ed. São Paulo: Editora Cultrix, 1973.

MELlO, João Manuel Cardoso de. O Capitalismo Tardio: contribuição à revisão crítica da formação e do desenvolvimento da economia brasileira. São Paulo: Editora Brasiliense, 1982.

MELO, Luciana Maria de Moura. A utopia de uma raça cósmica: o olhar de José Vasconcelos sobre a américa latina. 2010. Dissertação (História). Departamento de História, Pontifícia Universidade Católica de Goiás, Goiânia, 2010.

MOREIRA, Luiza Franco. Meninos, poetas e heróis: aspectos de Cassiano Ricardo do modernismo ao Estado Novo. São Paulo: Editora da Universidade de São Paulo, 2001.

MOTTA, Marly Silva da. A nação faz cem anos: a questão nacional no centenário da independência. Rio de Janeiro: Editora FGV: CPDOC, 1992.

MOURA, Denise Aparecida Soares de. Saindo das Sombras: Homens Livres no Declínio do Escravismo. Campinas: CMU Publicações, 1998. 
O ACTUAL MOMENTO LITERÁRIO. Correio Paulistano, São Paulo, 17 de mai. 1929 , p. 4.

OLIVEIRA, Lélio Luiz de. Economia e História: Franca século XIX. São Paulo: UNESP, 1997.

PRADO JR., Caio. História econômica do Brasil. São Paulo: Brasiliense, 1969.

QUEIROZ, Helaine Nolasco. Verdeamarelo/Anta e Antropofagia: narrativas da identidade nacional brasileira. 2010. 247 f. Dissertação (História Social da Cultura). Departamento de História da Faculdade de Filosofia e Ciências Sociais, Belo Horizonte, 2010.

RICARDO, Cassiano; SALGADO, Plínio Salgado. O Curupira e o Carão. São Paulo: Editora Hélios, 1927a.

RICARDO, Cassiano. Martim Cererê e seus novos poemas. $4^{\mathrm{a}}$ ed. São Paulo: Editora Novíssima, 1934. 178 p.

RICARDO, Cassiano. Martim Cererê ou o Brasil dos meninos, dos poetas e dos heróis. São Paulo: Editora Hélios, 1928.

RICARDO, Cassiano. Martim Cererê. 2a ed. São Paulo: Editora Hélios, 1929.

RICARDO, Cassiano. Martim Cererê. $3^{\mathrm{a}}$ ed. São Paulo: Revista dos Tribunais, 1932.

RICARDO, Cassiano. Martim Cererê. $5^{\text {a }}$ ed. São Paulo: Companhia Editora Nacional, 1936.

RICARDO, Cassiano. Martim Cererê. São Paulo: Editora Hélios, 1927b.

RICARDO, Cassiano. O Curupira e o Carão. In: PICCHIA, Menotti del.; RICARDO, Cassiano.; SALGADO, Plínio Salgado. O Curupira e o Carão. São Paulo: Editora Hélios, 1927a. p. 63-70.

SALGADO, Plínio. Epígrafe. In. RICARDO, Cassiano. Martim Cererê. São Paulo: Editora Hélios, 1927b.

SANDES, Noé Freire. A invenção da nação: entre a monarquia e a república. Goiânia: Editora UFG, 2011.

SCHWARCZ, Lilia Moritz. O espetáculo das raças: cientistas, instituições e questão racial no Brasil - 1870-1930. São Paulo: Companhia das Letras, 1993. $287 \mathrm{p}$. 
SILVA, Maria Cláudia Reis. A fotomontagem no Brasil: um estudo das obras de Athos Bulcão (1952-1956). 2014. 155 f. Dissertação (Artes Visuais). Universidade Federal de Goiás, Faculdade de Artes Visuais, Goiânia-GO, 2014.

SILVA, Sérgio. Expansão Cafeeira e Origens da Indústria no Brasil. São Paulo: Editora Alfa-Omega, 1986.

TOSI, Pedro Geraldo. Capitais no interior: Franca e a história da indústria coureiro-calçadista (1860-1945). 1998. 276p. Tese (doutorado) - Universidade Estadual de Campinas, Instituto de Economia, Campinas, SP. 1998.

VELLOSO, Mônica. História \& Modernismo. Belo Horizonte: Autêntica Editora, 2010.

Recebido em: 31 de maio de 2020

Aceito em: 9 de setembro de 2020 